\title{
A Three-Step, Single Session Therapy Intervention for COVID-Related Anxiety in a Pediatric Emergency Department
}

\author{
Diane P. Lee ${ }^{1}$, Scott A. Simpson ${ }^{2}$ \\ 1. Psychiatry, University of Colorado Anschutz Medical Campus, Aurora, USA 2. Psychiatric Emergency Services, \\ Denver Health Medical Center, Denver, USA
}

Corresponding author: Diane P. Lee, dianelee1613@gmail.com

\begin{abstract}
The novel Coronavirus disease (COVID-19) pandemic has led to increases in anxiety and depression, and mental health-related emergency department visits remain frequent despite overall changes in ED utilization. Here, we present a case of COVID-related anxiety and demonstrate the utility of a brief, singlesession therapy intervention delivered in the ED. The growing mental health burden of COVID-19 suggests that pediatric health care providers will treat patients with COVID-related anxiety during this pandemic. This case demonstrates a common presentation of somatization of anxiety and outlines a three-step, cognitive-behavioral intervention that can be particularly effective in treating COVID-related anxiety in the context of a single ED or medical visit.
\end{abstract}

Categories: Emergency Medicine, Pediatrics, Psychology

Keywords: integrated behavioral health, pediatric emergency department, psychiatric emergency, covid-19

\section{Introduction}

Before the novel coronavirus disease (COVID-19) pandemic, mental health visits to pediatric emergency departments were increasingly common. Over half a million children present to EDs for mental health reasons each year and EDs serve as the first point of contact for most children presenting with acute psychiatric issues [1]. Psychiatric visits are especially common among children from lower socioeconomic status backgrounds who have limited access to health care [2]. Furthermore, mental health symptoms are common among all children in the ED: almost half of the patients presenting to pediatric EDs meet the criteria for an anxiety disorder [3]. The COVID-19 pandemic has led to increases in anxiety and depression [4], and mental health-related ED visits remain frequent despite overall changes in ED utilization [5]. Children experience anxiety related to the epidemic and the health of relatives, poor sleep, physical discomfort, agitation, and separation anxiety [6].

Review began 12/17/2020 Review ended 12/23/2020 Published 12/29/2020

\section{(c) Copyright 2020}

Lee et al. This is an open access article distributed under the terms of the Creative Commons Attribution License CC-BY 4.0., which permits unrestricted use, distribution, and reproduction in any medium, provided the original author and source are credited.
Given that mental health symptoms often present initially as somatic complaints that require emergent medical assessment, pediatricians and pediatric health care providers will treat patients with COVID-related anxiety during this pandemic. Here, we present a case of one such presentation of somatization of anxiety in the ED and demonstrate the utility of brief single-session therapy intervention.

\section{Case Presentation}

A 10-year-old American Indian female was brought to the ED by her mother for chest pain, abdominal pain, nausea, and decreased appetite for the last several weeks. She had no significant medical or psychiatric history. Her vital signs and laboratory tests were reassuring. Upon initial assessment, the patient's mother voiced concerns about the patient's anxiety and distress related to COVID-19. The team offered the family consultation with the service's integrated behavioral health consultant [7].

With the consultant, the patient's mother reported that the COVID-19 pandemic had been difficult. The patient had been feeling "down" and experiencing increases in irritability, loss of pleasure (anhedonia), crying, racing thoughts, and worrying. The patient reported struggling with social isolation and being unable to see friends, as she was previously very active at school and with peers. Additionally, the patient worried about her family members contracting COVID; two of her siblings have chronic health conditions. She also worried that her abdominal pain was an indication of a serious health issue. The patient denied suicidal thoughts or substance use.

The behavioral health consultant began a brief cognitive-behavioral therapy (CBT) intervention. First, psychoeducation was provided on how common the patients' concerns are amid the pandemic and how somatic complaints are a frequent manifestation of anxiety. Together, the patient, her mother, and the clinician identified the goals of improving the patient's anxiety and finding ways for the patient to be more active despite physical distancing and quarantine restrictions. Coping skills and mindfulness training were provided so that the patient could manage episodes of anxiety and subsequent pain. During this teaching, 
the clinician identified cognitive distortions in the patient's thinking and emphasized precautions that the family was taking to remain healthy-thereby challenging the patient's catastrophic thinking that she needed to be doing more to protect her family. Additionally, the consultant reframed the patient's thoughts that she was unable to engage in positive activities given COVID restrictions by reminding her that she still had many options for preferred activities still available to her. To encourage more frequent healthy behaviors, the family was encouraged to maintain routine in the day and facilitate social connections despite physical distancing.

The patient's medical workup was reassuring, and other diagnoses or conditions unrelated to anxiety such as viral illness, appendicitis, and chest pain with cardiac etiology were assessed to be unlikely. At the time of ED discharge following this brief, CBT intervention, the patient reported significant decreases in anxiety level and somatic symptoms. Furthermore, the family felt reassured and motivated to reinforce the treatment plan discussed. In the six months following this visit, the patient had not returned to the ED.

\section{Discussion}

Even before the COVID-19 pandemic, mental health presentations, including somatization of anxiety, were common in the ED. Furthermore, almost half of mental health-related visits to pediatric EDs are repeat visits, which reflects the lack of training, consensus, and protocols for evidence-based treatments for mental health symptoms in the ED setting [8]. This case reflects a common presentation of COVID-related anxiety which is more often better treated through brief intervention than through medication or even referrals to treatment. Additionally, this case provides guidance around the implementation of an evidence-based intervention. Single-session therapy can be particularly effective in reducing anxiety and is well-suited to be integrated into and delivered in the context of a medical visit by pediatric healthcare providers [9].

The general structure and content of this brief intervention are detailed in Table 1. Clinicians start with (1) providing teaching around the patient's symptoms; this step not only teaches patients and families but also builds rapport before the following two steps. Next, the clinician (2) discusses cognitive and behavioral techniques for managing anxiety. Finally, (3) goals for aftercare are clearly identified. It is not uncommon for cognitive distortions-irrational thoughts that perpetuate anxiety-to arise during the assessment [10]. Table 2 lists common distortions and aids in challenging these distortions. Common cognitive distortions include catastrophization (assuming the worst possible outcome), fortune-telling (predicting negative outcomes), and black-and-white thinking (thinking exclusively in extremes). When using one of these reframing statements, the clinician should begin with a validating statement and then follow with a direct reframing of the patient's cognitive distortion.

\begin{tabular}{|c|c|c|c|}
\hline Step & Goal & Intervention & Potential Pitfalls \\
\hline \multirow[b]{2}{*}{$\begin{array}{l}1 . \\
\text { Psychoeducation }\end{array}$} & Provide validation and build rapport & Validate distress and anxiety & \multirow[b]{2}{*}{$\begin{array}{l}\text { Consider referral for follow-up if } \\
\text { symptoms persist beyond a single } \\
\text { session. }\end{array}$} \\
\hline & $\begin{array}{l}\text { Assess if the patient is experiencing the effects of a } \\
\text { discrete stressor (e.g., COVID) or the presence of } \\
\text { underlying mental health symptoms which will } \\
\text { require further follow up }\end{array}$ & $\begin{array}{l}\text { Teach patients about the somatic } \\
\text { manifestation of mental health } \\
\text { symptoms } \\
\text { Teach about the general mental } \\
\text { health burden of COVID }\end{array}$ & \\
\hline $\begin{array}{l}2 . \\
\text { Coping skills }\end{array}$ & Support healthier coping with anxiety & $\begin{array}{l}\text { Teach mindfulness-based coping } \\
\text { skills9 such as deep breathing, } \\
\text { body scans, or progressive } \\
\text { muscle relaxation } \\
\text { Challenge thought distortions } \\
\text { (Table 2) }\end{array}$ & $\begin{array}{l}\text { If the patient's coping } \\
\text { mechanisms include substance } \\
\text { abuse or self-harming, further } \\
\text { safety assessment is needed. }\end{array}$ \\
\hline $\begin{array}{l}3 . \\
\text { Behavioral } \\
\text { activation }\end{array}$ & $\begin{array}{l}\text { Increase the frequency of healthy and enjoyable } \\
\text { behaviors }\end{array}$ & $\begin{array}{l}\text { Set goals related to maintaining a } \\
\text { regular routine and social } \\
\text { connection despite COVID } \\
\text { restrictions }\end{array}$ & $\begin{array}{l}\text { Patients with complex social } \\
\text { stressors (e.g., homelessness) are } \\
\text { likely to need additional support } \\
\text { and resources. }\end{array}$ \\
\hline
\end{tabular}

TABLE 1: A Three-Step, Brief CBT Intervention for Managing COVID-Related Anxiety

CBT: cognitive-behavioral therapy 


\section{Cureus}

\begin{tabular}{|c|c|c|}
\hline Patient Statement & $\begin{array}{l}\text { Type of } \\
\text { Distortion }\end{array}$ & Retramıng Statement \\
\hline "COVID will never end." & Catastrophization & $\begin{array}{l}\text { "I know it seems endless, but we have had pandemics before, and things got better. Many } \\
\text { other places are already doing better." }\end{array}$ \\
\hline $\begin{array}{l}\text { "I'm going to get my whole } \\
\text { family sick" }\end{array}$ & Catastrophizatıon & $\begin{array}{l}\text { "I know you are worried about your family getting sick. Remember that you are doing a good } \\
\text { job being careful and you are already doing everything you can to follow the safety } \\
\text { guidelines." }\end{array}$ \\
\hline wrong with me." & $\begin{array}{l}\text { Catastrophization } \\
\text { and somatization }\end{array}$ & $\begin{array}{l}\text { worried, they often also feel pain in their stomach or chest. This does not mean that you are } \\
\text { really sick or that you have COVID." }\end{array}$ \\
\hline $\begin{array}{l}\text { "My parents will get COVID } \\
\text { and die" }\end{array}$ & $\begin{array}{l}\text { Catastrophization } \\
\text { and fortune } \\
\text { telling }\end{array}$ & $\begin{array}{l}\text { stay healthy and that doctors are working hard to take care of people who do get sick. Most } \\
\text { people recover from COVID." }\end{array}$ \\
\hline $\begin{array}{l}\text { "I can't do anything fun } \\
\text { because of COVID. I just have } \\
\text { to do nothing." }\end{array}$ & $\begin{array}{l}\text { Black-and-white } \\
\text { thinking }\end{array}$ & $\begin{array}{l}\text { "It feels like you cannot do anything fun right now because of COVID and it IS so hard to stay } \\
\text { friends even if you can't see them." }\end{array}$ \\
\hline
\end{tabular}

\section{TABLE 2: Common Thought Distortions Amid COVID and Responses}

\section{Conclusions}

Cognitive-behavioral therapy is a therapeutic philosophy that encourages behavior change as a way to reduce anxiety and depression, as one's behaviors and emotions are inextricably linked. Furthermore, brief therapy is most helpful in the context of a discrete stressor as with COVID-19. This case demonstrates how pediatricians and pediatric health care providers can apply a brief, evidence-based CBT intervention, which is well-suited for presentations of COVID-related anxiety particularly in the context of a single medical visit. Additionally, this case reminds clinicians of the importance of providing quality mental health interventions for underserved patients who frequently present to the ED. Consistent with the effectiveness of evidence-based, single-session interventions, the patient presented in this case reported significant decreases in anxiety by the time of discharge. Furthermore, although almost half of mental health ED visits are repeat visits, this patient has not returned to the ED, which serves as another potential measure of effectiveness.

Given the pandemic's mental health impact on children and families, pediatricians and pediatric health care providers will treat patients with COVID-related anxiety. Furthermore, pediatricians' and pediatric health care providers' skills will be both challenged and needed in this time of heightened anxiety around COVID19.

\section{Additional Information}

\section{Disclosures}

Human subjects: Consent was obtained by all participants in this study. Conflicts of interest: In compliance with the ICMJE uniform disclosure form, all authors declare the following: Payment/services info: All authors have declared that no financial support was received from any organization for the submitted work. Financial relationships: All authors have declared that they have no financial relationships at present or within the previous three years with any organizations that might have an interest in the submitted work. Other relationships: All authors have declared that there are no other relationships or activities that could appear to have influenced the submitted work.

\section{References}

1. Sheridan DC, Spiro DM, Fu R, et al.: Mental health utilization in a pediatric emergency department. Pediatr Emerg Care. 2015, 31:555-559. 10.1097/PEC.0000000000000343

2. Gill PJ, Saunders N, Gandhi S, Gonzalez A, Kurdyak P, Vigod S, Guttmann A: Emergency department as a first contact for mental health problems in children and youth. J Am Acad Child Adolesc Psychiatry. 2017, 56:475-482. 10.1016/j.jaac.2017.03.012

3. Ramsawh HJ, Chavira DA, Kanegaye JT, Ancoli-Israel S, Madati PJ, Stein MB: Screening for adolescent anxiety disorders in a pediatric emergency department. Pediatr Emerg Care. 2012, 28:1041-1047. 10.1097/PEC.0b013e31826cad6a

4. Rajkumar RP: COVID-19 and mental health: a review of the existing literature . Asian J Psychiatr. 2020, 52:102066. 10.1016/j.ajp.2020.102066 


\section{Cureus}

5. Hartnett KP, Kite-Powell A, DeVies J, Coletta MA, Boehmer TJ, Adjemian J, Gundlapalli AV: Impact of the COVID-19 pandemic on emergency department visits-United States, January 1, 2019-May 30. 2020. MMWR Morb Mortal Wkly Rep 2020, 69:699-704. 10.15585/mmwr.mm6923e1

6. Jiao WY, Wang LN, Liu J, Fang SF, Jiao FY, Pettoello-Mantovani M, Somekh E: Behavioral and emotional disorders in children during the COVID-19 epidemic. J Pediatr. 2020, 221:264-266.

10.1016/j.jpeds.2020.03.013

7. Casher G, Simpson S, Gagnon K: Integrated behavioral health in the pediatric emergency department: program development, implementation, and future directions. AAEP. 2018, 9-14.

8. Leon SL, Cloutier P, Polihronis C, Zemek R, Newton AS, Gray C, Cappelli M: Child and adolescent mental health repeat visits to the emergency department: a systematic review. Hosp Pediatr. 2017, 7:177-186.

10.1542/hpeds.2016-0120

9. Schleider JL, Weisz JR: Little treatments, promising effects? meta-analysis of single-session interventions for youth psychiatric problems. J Am Acad Child Adolesc Psychiatry. 2017, 56:107-115.

10.1016/i.jaac.2016.11.007

10. Burns, D: Feeling Good: The New Mood Therapy. Harper, New York; 2012. 